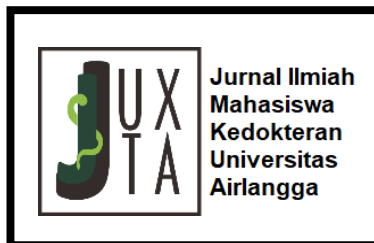

\title{
Profile of Diabetes Mellitus in Benign Protate Hyperplation's Patients with Urinary Retention in Dr. Soetomo 2016
}

\author{
Ahmad Zaidan Ni'am Abu Adha ${ }^{1}$, Reny l'tishom ${ }^{2}$, Fikri Rizaldi ${ }^{3}$, Doddy M. Soebadi ${ }^{3}$ \\ ${ }^{1}$ Medical Education, Faculty of Medicine, Universitas Airlangga, Surabaya, Indonesia. \\ 2 Department of Medical Biology, Faculty of Medicine, Universitas Airlangga, Surabaya, Indonesia. \\ ${ }^{3}$ Department of Urology, Faculty of Medicine, Universitas Airlangga - Dr. Soetomo General Hospital, Surabaya, Indonesia.
}

\begin{tabular}{|c|c|}
\hline A B S TRACT & ARTICLE INFO \\
\hline $\begin{array}{l}\text { Introduction: Benign prostatic hyperplasia (BPH) develops inevitably } \\
\text { related to age in almost all men starting around the age of } 40 \text { years. LUTS } \\
\text { is the most common manifestation of BPH. There were several risk factors } \\
\text { that play a role in the BPH and LUTS, one of which is diabetes mellitus. The } \\
\text { incidence of diabetes mellitus is increasing throughout the world. In } 2015 \text {, it } \\
\text { was estimated that } 30.3 \text { million Americans }(9.4 \%) \text { and } 3.4 \text { million Canadians } \\
(9.3 \%) \text { were diagnosed with diabetes. About } 5 \%-10 \% \text { are diagnosed with } \\
\text { type I, and around } 90 \%-95 \% \text { are diagnosed with type II. The burden of the } \\
\text { disease caused by diabetes is quite high and continues to increase in every } \\
\text { country. It is estimated that the global prevalence of people with diabetes in } \\
2013 \text { as many as } 382 \text { million people will increase to } 592 \text { million by } 2035 \text {. } \\
\text { The exact etiology of BPH is still unknown. Acute urinary retention (AUR) is } \\
\text { the most frequent urological emergency. This study aims to find out the } \\
\text { number of occurrences of diabetes mellitus in BPH patients with urinary } \\
\text { retention in Dr. Soetomo General Hospital from January to December } 2016 \text {. }\end{array}$ & $\begin{array}{l}\text { Article history: } \\
\text { Received } 07 \text { August } 2019 \\
\text { Received in revised form } 16 \\
\text { August } 2019 \\
\text { Accepted } 23 \text { August } 2019\end{array}$ \\
\hline
\end{tabular}

Methods: This research used descriptive research design. Population in this study was BPH patients with acute urinary retention in Dr. Soetomo General Hospital in 2016. The total sampling method was used. The variable studied was diabetes mellitus. The data was obtained from the patient's medical record.

Results: In this study, 62 subjects were found with 11 subjects with positive diabetes mellitus (17.7\%) and 43 subjects with negative diabetes mellitus (69.4\%).

Conclusion: From the results of the study, it was found that there were $17.7 \%$ of $\mathrm{BPH}$ patients with acute urinary retention who had diabetes mellitus.

*Correspondence: ritishom@fk.unair.ac.id JUXTA: Jurnal IImiah Mahasiswa Kedokteran Universitas Airlangga p-ISSN: 1907-3623; e-ISSN: 2684-9453

DOI: $10.20473 / j u x t a . V 10122019.71-73$

Open access under Creative Commons Attribution-ShareAlike 4.0 International License (CC-BY-SA)

$$
\text { (c) (i) (2) }
$$




\section{Introduction}

Benign prostatic hyperplasia (BPH) is smooth muscle and prostate gland epithelial cells hyperplasia in the transition zone. ${ }^{1,2} \mathrm{BPH}$ develops inevitably related to age in almost all men starting around the age of 40 years. A large cohort study in the United States stated that men aged 40 to 83 have an overall incidence of 4.5 to $6.8 / 1000$ men/year. The incidence increases with age, so men in their 70 s have $10 \%$ and in their 80 s are more than $30 \%$ likely to suffer from AUR. ${ }^{3}$

In fact, many men with new histological BPH see a doctor when this condition becomes a clinical entity and is accompanied by subjective symptoms, LUTS is the most common manifestation. ${ }^{4}$ LUTS symptoms consist of storage symptoms, voiding symptoms, and post voiding symptoms. ${ }^{5}$ This has a negative effect on quality of life. ${ }^{6}$ $\mathrm{BPH}$ is the most common cause of urinary retention. ${ }^{3}$

Common risk factors that play a role in the BPH and LUTS population are age, hormonal, genetic, inflammatory, and lifestyle factors. Diabetes is one of the factors that increase the risk of $\mathrm{BPH}^{7}$ However, the exact etiology of $\mathrm{BPH}$ is still unknown. ${ }^{2}$

Diabetes mellitus is a chronic disease caused by inherited and/or acquired deficiency in the production of insulin by the pancreas, or by the ineffectiveness of the insulin produced. ${ }^{8}$ Diabetes is a group of metabolic diseases characterized by hyperglycaemia due to defects in insulin secretion, insulin action, or both. Chronic diabetes with hyperglycaemia is associated with long-term damage, dysfunction and failure of different organs, especially the eyes, kidneys, nerves, heart, and blood vessels. ${ }^{9}$

In the development of diabetes several pathogenic processes are involved. The process revolves around the destruction of autoimmune $\beta$ cells with insulin deficiency as a result of abnormalities that result in resistance to insulin action. Deficiency of insulin action caused by inadequate insulin secretion and or reduced tissue response to insulin at one or more points on the complex pathway of hormone action. $^{9}$

Diabetes mellitus increases the risk of BPH and LUTS significantly based on epidemiological evidence, with pathophysiological mechanisms such as insulin-stimulated prostate growth and associated trophic factors, increased sympathetic tone, oxidative stress, and systemic inflammation induction. ${ }^{6}$

Acute urinary retention (AUR) is the most frequent urological emergency. AUR is sudden urinary retention, unable to urinate even though the bladder is full, which is often accompanied by pain in the suprapubic part. It is contrary to chronic urinary retention that is not accompanied by pain or painless. ${ }^{3,}{ }^{10}$ AUR is most often caused by obstruction, but can also be caused by trauma, drugs, neurological diseases, infections and sometimes psychological problems. ${ }^{11}$

Previous studies showed that BPH might be directly related to hyperglycemia and urinary retention. Others showed no association between the conditions, while others showed an inverse relationship between diabetes and clinical BPH. A number of high-quality large studies have shown an association between hyperglycemia and insulin resistance with LUTS. ${ }^{6}$

\section{Methods}

This study has received a certificate of ethical clearance from the ethical committee in health research Dr. Soetomo General Hospital. The descriptive research design was used. The population in this study was BPH patients with urinary retention in Dr. Soetomo General Hospital from January to December 2016. The subjects of this study were patients who were diagnosed with $\mathrm{BPH}$ with urinary retention. The exclusion of this study is $\mathrm{BPH}$ patients with acute urinary retention whose medical records were absent or lost. The total sampling method was used.

The research variable was diabetes mellitus. Diabetes mellitus is defined if there was a history of diabetes mellitus or random plasma glucose test results $>200 \mathrm{mg} / \mathrm{dl}$, FPG $>126 \mathrm{mg} / \mathrm{dl}$, 2-h PG >200mg/dl. All data were obtained from medical records of $\mathrm{BPH}$ patients with acute urinary retention in Dr. Soetomo General Hospital in 2016, including inpatient and outpatient medical records.

\section{Results}

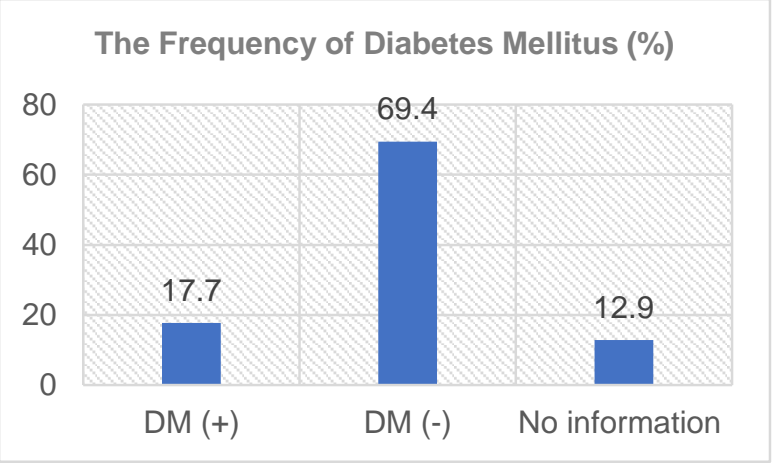

Figure 1. The frequency of diabetes mellitus.

There were 11 positive diabetes mellitus subjects (17.7\%), 43 negative diabetes mellitus subjects $(69.4 \%)$, and 8 subjects had no information (12.9\%).

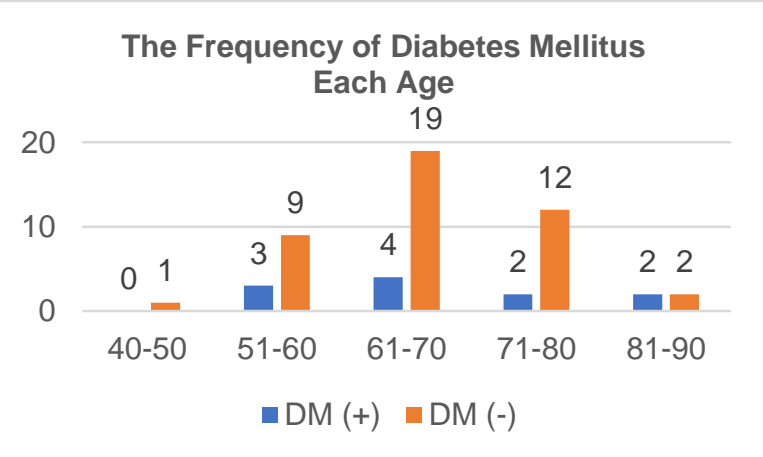

Figure 2. The frequency of diabetes mellitus in each age.

From the research data, it was found that in subjects aged 40-50 years there were no diabetes mellitus. In subjects aged 51-60 years, there were 3 subjects of positive 
diabetes mellitus fewer than negative diabetes mellitus with 9 subjects. In subjects aged 61-70 years, there were 4 positive diabetes mellitus subjects fewer than negative diabetes mellitus with a total of 19 subjects. In subjects aged 71-80 years, there were 2 subjects of positive diabetes mellitus fewer than negative diabetes mellitus with a total of 12 subjects. In subjects aged 81-90 years, there were 2 positive diabetes mellitus with the same number of negative diabetes mellitus.

\section{Discussion}

The results of this study showed that the number of $\mathrm{BPH}$ subjects with acute urinary retention who suffer from diabetes mellitus is less than that of patients who do not have diabetes mellitus. Diabetes is one of the factors that increase the risk of $\mathrm{BPH}$. The high concentration of insulinlike growth factor-1 (IGF-1) and insulin-like growth factor binding protein-3 (IGFBP-3) in diabetic patients can increase the risk factor of $\mathrm{BPH}$ clinically. The risk of $\mathrm{BPH}$ increases in patients who have elevated serum insulin, high fasting blood sugar, and diabetes diagnosed. ${ }^{7}$

In people with diabetes the urinary period more elongated gradually. Besides that the contractility of the detrusor and bladder muscles decreases, the urinary sensation decreases, and the residual volume increases which will eventually become urinary retention. This has led to increasing the risk of urinary retention in $\mathrm{BPH}$ patients. Up to $45 \%$ of diabetes mellitus patients and 75 to 100 patients with diabetic peripheral neuropathy will develop bladder dysfunction which resulted in urinary retention. . $^{3,10}$

$45 \%$ of patients with diabetes mellitus are thought to have diabetic cystography. ${ }^{6}$ An Italian study of 271 tertiary centers was found in simple prostatectomy increasing glycemic levels not related to prostate volume greater than $60 \mathrm{~cm}^{3} .{ }^{12}$ A convenience sample $(n=117)$ of 60 years of age from China showed that diabetes had increased prostate volume (41.18 versus $51.52 \mathrm{~cm} 3, \mathrm{p}=0.005)$ and increased PSA (1.94 v. 3.23, $p=0.013$ ).

Metformin suppresses the expression of IGF-1R and IGF-1 secretion in stromal cells so that it can inhibit the proliferation of benign prostatic epithelial cells. Metformin simultaneously increases the G0/G1 population and lowers the G2/M cell population. Findings here might have significant clinical implications in the management of $\mathrm{BPH}$ patients treated with metformin. ${ }^{13}$

Diabetes mellitus is a chronic disorder associated with urinary retention and hyperglycaemia, secondary to metabolism of carbohydrates, fats, and abnormal proteins. Diabetes mellitus is a modifiable risk factor because it can be influenced through diet and exercise, it shows that $\mathrm{BPH}$ can be prevented or improved through modification of the metabolic pathway. ${ }^{6}$

Diabetes, hyperglycaemia, and insulin resistance are associated with BPH/LUTS (Figure 3). Increased sympathetic nerve activity has a relationship with the incidence of hyperinsulinemia. With increased sympathetic nerve activity, there is an increase in prostate smooth muscle tone and subsequent bladder outlet obstruction. In diabetes, an increase in secondary insulin concentration provides trophic effects which later lead to prostate size. The development of $\mathrm{BPH}$ and prostate cancer has an involvement with dysregulation of the insulin-like growth factor (IGF) axis. Many organs including the prostate, physiological and pathophysiological growth are regulated by IGF axis. Insulin has structural similarities with IGF so it joins the IGF receptor to enter prostate cells. This allows the activation of receptors to induce growth and proliferation. Insulin can increase the transcription of genes involved in the metabolism of sex hormones that affect the environment of the prostate hormone. Chronic proinflammatory state associated with metabolic syndrome, hyperglycemia, and hyperinsulinemia, have contributed to the BPH/LUTS. ${ }^{6}$

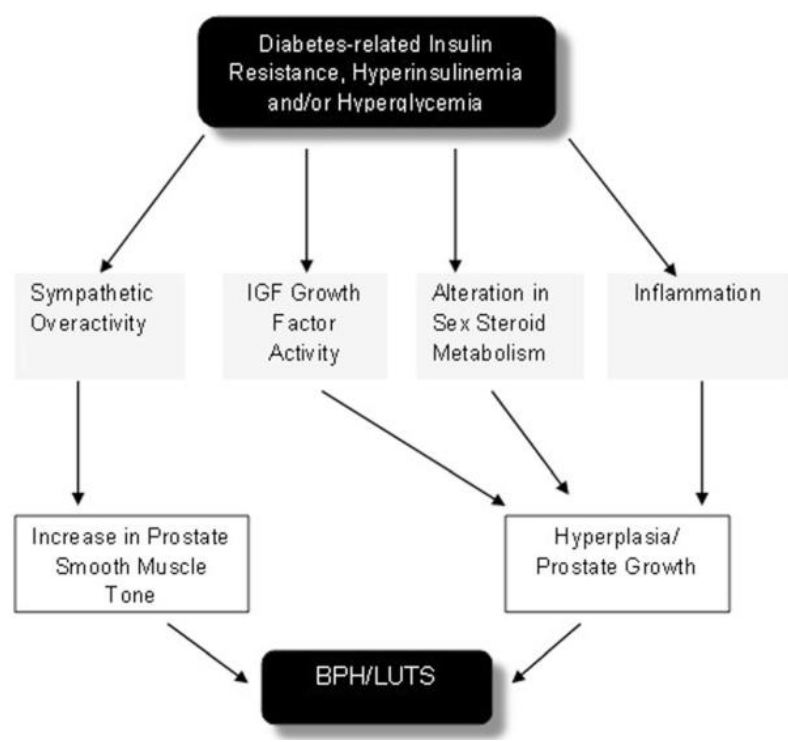

Figure 3. Mechanisms of diabetes, hyperglycaemia, and insulin resistance in the pathogenesis of BPH/LUTS. ${ }^{6}$

The results of this study found that the number of subjects who suffered from diabetes mellitus was less than those who did not have diabetes mellitus. This can be caused by this study using subjects and medical records from urology so that they have been screened before.

\section{Conclusion}

From the results of the study, it was found that there were $17.7 \%$ of $\mathrm{BPH}$ patients with acute urinary retention who had diabetes mellitus.

\section{CONFLICT OF INTEREST}

The author stated there is no conflict of interest in this study.

\section{REFERENCES}

1. McVary KT, Roehrborn CG, Avins AL, et al. Update on AUA guideline on the management of benign prostatic hyperplasia. The Journal of urology. 2011; 185: 1793803. 
2. Oelke M, Höfner K, Jonas U, Laval K-U and Tunn U. Benign Prostatic Hyperplasia: Terminology and Assessment. Deutsches Ärzteblatt. 2007; 104: 2261-7.

3. Selius B and Subedi R. Urinary Retention in Adults: Diagnosis and Initial Management. American Academy of Family Physicians. 2008; 77: 643-6.

4. Roehrborn CG. Benign prostatic hyperplasia: an overview. Rev Urol. 2005; 7 Suppl 9: S3-S14.

5. Chapple $\mathrm{C}$ and Abrams P. Male Lower Urinary Tract Symptoms (LUTS): An International Consultation on Male LUTS. Montréal: Société Internationale d'Urologie, 2013.

6. Breyer BN and Sarma AV. Hyperglycemia and insulin resistance and the risk of BPH/LUTS: an update of recent literature. Current urology reports. 2014; 15: 462.

7. Parsons JK. Benign Prostatic Hyperplasia and Male Lower Urinary Tract Symptoms: Epidemiology and Risk Factors. Curr Bladder Dysfunct Rep. 2010; 5: 212-8.

8. Organization WH. Diabetes mellitus: (2018, accessed November 23rd 2018).

9. American Diabetes A. Diagnosis and classification of diabetes mellitus. Diabetes care. 2010; 33 Suppl 1: S62-S9.

10. Nyman MA, Schwenk NM and Silverstein MD. Management of urinary retention: rapid versus gradual decompression and risk of complications. Mayo Clinic proceedings. 1997; 72: 951-6.

11. Curtis LA, Dolan TS and Cespedes RD. Acute urinary retention and urinary incontinence. Emergency medicine clinics of North America. 2001; 19: 591-619.

12. Gacci M, Vignozzi L, Sebastianelli A, et al. Metabolic syndrome and lower urinary tract symptoms: the role of inflammation. Prostate cancer and prostatic diseases. 2013; 16: 101-6.

13. Wang Z, Xiao X, Ge R, et al. Metformin inhibits the proliferation of benign prostatic epithelial cells. PloS one. 2017 ; 12: e0173335. 